\title{
Control of Enterotoxigenic Escherichia coli in Ground Beef by Blends of Essential Oils
}

\section{Alline Aparecida Souza ${ }^{1}$, Natália Jubram Zeneratto ${ }^{1}$, Roberta Hilsdorf Piccoli1,2* Suzan Kelly Vilela Bertolucci ${ }^{3}$}

${ }^{1}$ Food Microbiology Laboratory, Universidade Federal de Lavras, Lavras, MG, Brazil

${ }^{2}$ Food Science Department, Universidade Federal de Lavras, Lavras, MG, Brazil

${ }^{3}$ Agriculture Department, Universidade Federal de Lavras, Lavras, MG, Brazil

Email: *rhpiccoli@dca.ufla.br

How to cite this paper: Souza, A.A., Zeneratto, N.J., Piccoli, R.H. and Bertolucci, S.K.V. (2018) Control of Enterotoxigenic Escherichia coli in Ground Beef by Blends of Essential Oils. Advances in Microbiology, 8, 917-930.

https://doi.org/10.4236/aim.2018.812061

Received: October 19, 2018

Accepted: December 8, 2018

Published: December 11, 2018

Copyright $\odot 2018$ by authors and Scientific Research Publishing Inc. This work is licensed under the Creative Commons Attribution International License (CC BY 4.0).

http://creativecommons.org/licenses/by/4.0/

\begin{abstract}
Different combinations of essential oils from cinnamon, cloves, oregano, and thyme were evaluated in vitro for their bactericidal activity against enterotoxigenic Escherichia coli (ETEC). The solutions containing cinnamon $(0.03 \%)$, oregano $(0.16 \%)$, and thyme $(0.08 \%)(\mathrm{P} 1)$; and clove $(0.08 \%)$, oregano $(0.33 \%)$, and thyme $(0.04 \%)(\mathrm{P} 2)$, exhibited high bactericidal activity, and were selected for use as preservatives in ground beef inoculated with ETEC and refrigerated. The two preservative solutions (P1 and P2) exhibited significant bactericidal action $(\mathrm{p}<0.05)$ on ETEC, with ETEC reductions of 1.03 and of $0.87 \mathrm{LogUFC} / \mathrm{g}$ in the beef samples treated with P1 and P2, respectively. GC-MS analysis of the oil mixtures showed both preservatives to contain significant concentrations of carvacrol. Chromatic degradation was not observed in the samples treated with preservatives. Essential oil mixtures thus concocted are therefore potential preservative candidates in ground beef, as they are capable of controlling ETEC contamination while preserving the products' coloration.
\end{abstract}

\section{Keywords}

Essential Oils, Meat Color, Synergistic Activity, Food Safety

\section{Introduction}

Escherichia coli is a facultatively aerobic bacteria that can be found in the intestinal microbiota of humans and warm-blooded animals. It is considered to be an innocuous commensal bacterium; it can, however, cause a variety of infections. There are three clinical syndromes resulting from infections with pathogenic strains of $E$. coli: urinary tract infection, meningitis/sepsis, and diarrheal condi- 
tions [1].

These different syndromes are caused by different $E$. coli pathogens, among which enterotoxigenic E. coli (ETEC) may be said to stand out. ETEC is known for causing travelers' diarrhea syndrome, a symptom of which is watery diarrhea, generally without mucus, pus, or blood. Fever or vomiting is not observed as often. Although it is normally brief, self-limiting, and not very intense, the diarrhea can be intense [2].

The pathogenicity of the lines of ETEC is a result of the production of thermolabile and thermostable enterotoxins and of at least 25 different colonization factors, which target the intestinal mucous membrane. Although food-borne outbreaks in developed countries are few and sporadic, isolated ETEC strains at the university of Gothenburg, Sweden from 1980 to 2011 showed distinct colonization factors and enterotoxin profiles, with the appearance of emerging strains that endow this bacterium with greater transmissibility and infectious capacity [3], highlighting its importance as an emerging human pathogen and now ETEC is recognized as a common cause of foodborne outbreaks in childrens and adults [4].

Although various products have been associated with outbreaks of food-borne diseases, infections caused by $E$. coli are mainly caused by consumption of contaminated meat and water. During animal slaughter, even with good manufacturing practices, microbiological contamination of bovine carcasses is often evident, and $E$. coli is the most frequently found microorganism. In addition to contamination during slaughter, inadequate handling of meat further increases contamination [2].

Consumption of ground beef stands out, as it is a popular product used in meals in practical and diverse ways. Due to some of its intrinsic characteristics, meat, and especially ground meat constitute a rich medium for microbial growth.

Various strategies have been used and suggested for increasing the shelf-life and safety of meat products in the food industry. The use of natural antimicrobial agents and antioxidants has been greatly cited, with essential oils progressively assuming a prominent role [5] [6].

Essential oils are formed by a number of plant species, and are derived from secondary metabolic processes. They are complex mixtures of volatile, lipophilic, generally odoriferous liquid substances that may contain up to 60 different components in various concentrations. However, they are commonly found to contain two or three predominant components (20\% - 70\%) [7].

Most essential oils consist of components from the class of phenylpropanoids or terpenoids, with a predominance of the latter [8]. They have antimicrobial properties on various microorganisms and have been shown to be antioxidants [9] [10] [11] [12].

Essential oils derived from plants used for spice production are classified as "generally recognized as safe (GRAS)" and widely accepted by consumers [13] [14]. In addition, they are classified as natural flavorings and their permitted use 
in foods. Due to the food sector's growing need of reducing the use of chemical preservatives while maintaining food safety, the development of essential-oil-based preservatives has come to attract great interest. However, few preservatives containing essential oils are commercially available. "DMC Base Natural", a preservative produced by DOMCA S.A. (Alhendin, Granada, Spain), is composed of essential oils of rosemary, sage, and citrus (50\%) and glycerol (50\%). "Protecta One" and "Protecta Two" are mixtures of herb extracts produced by Bavária Corp. USA. These preservatives are seemed as GRAS (Generally recognized as safe).

The essential oils of cinnamon (Cinnamomum cassia Nees ex Blume), clove (Syzygium aromaticum Thumb.), oregano (Origanum vulgare L.), and thyme (Thymus vulgaris L.), are known for exhibiting high antimicrobial activity. However, for an essential oil to maintain its high antimicrobial activity when added to foods, its concentration must normally be greater than the concentration required for antimicrobial activity in vitro. Jayasena \& Jo [15], in a review study, show that, in most antimicrobial evaluations of essential oils in meat products, only one essential oil is used and usually at high concentration, as shown in the study with ground beef, that was necessary more than $1 \%$ of essential oil of two species of Thymusto inhibit the growth of E. coli, Salmonella thyphimurium and Staphylococcus aureus [16]. This often leads to decharacterization of the food products and therefore to difficulty in using essential oils as food preservatives. An alternative to this problem is the study of the synergistic antimicrobial activity of diverse essential oils.

In this sense, the aim of this study was to evaluate the antimicrobial effect of two preservatives, prepared from the essential oils of Thymus vulgaris, Cinnamomum cassia, and Origanum vulgare L., and from those of T. vulgaris, Syzygium aromaticum, and $O$. vulgare, on enterotoxigenic Escherichia coli inoculated in refrigerated ground beef, as well as the oil blends' influence over the chromatic characteristics of the meat.

\section{Materials and Methods}

\subsection{Essential Oils}

The essential oils used were acquired from Ferquima Indústria e Comércio Ltda (Vargem Grande Paulista, São Paulo, Brazil). Essential oils from the leaves and bark of Cinnamomum cassia Nees exBlume (cinnamon), flower buds of Syzygium aromaticum Thumb. (Cloves), leaves of Origanum vulgare L. (oregano), and leaves and flowers of Thymus vulgaris L. (thyme) were used. These oils were chosen based on the best results observed for minimum inhibitory concentration in vitro on ETEC [17].

\subsection{Microorganism, Maintenance, Standardization, and Acquisition of the Inoculum}

Enterotoxigenic Escherichia coli (ETEC) ATCC 35401 was provided by the En- 
terobacteria Laboratory (Laboratório de Enterobactérias-LABENT) of the Instituto Oswaldo Cruz (IOC/FIOCRUZ). The stock culture, stored in a frozen medium (glycerol-15 mL; bacteriological peptone $-0.5 \mathrm{~g}$; yeast extract- $0.3 \mathrm{~g}$; $\mathrm{NaCl}-0.5 \mathrm{~g}$; distilled water $-100 \mathrm{~mL}$; $\mathrm{pH}$ between 7.2 and 7.4 ), was activated by transfer of culture aliquots to tryptone soy broth (TSB) and incubated at $37^{\circ} \mathrm{C}$ for 24 hours. Inoculum standardization (approximately $10^{8} \mathrm{CFU} / \mathrm{mL}$ ) was accomplished with a growth curve. Optic density (A600 nm) was monitoredalong with plate counting, on trypticase soy agar (TSA) with incubation at $37^{\circ} \mathrm{C}$ for 24 hours.

\subsection{In Vitro Bactericidal Action of the Combinations of Essential Oils on ETEC}

The antimicrobial activities of different combination of essential oils of cinnamon, cloves, oregano, and thyme on ETEC were evaluated.

The essential oils, combined three by three, were evaluated at different proportions (Table 1).

The minimum bactericidal concentration (MBC) of the essential oil combinations was determined on 96-well plates. The oil combinations were prepared in TSB with the addition of $0.5 \%$ Tween 80 in the proportions shown in Table 1 . $150 \mu \mathrm{L}$ of the prepared solutions were subsequently added to the microplate wells, along with $10 \mu \mathrm{L}$ of the standardized culture. The microplates were sealed and incubated in a B.O.D. chamber at $37^{\circ} \mathrm{C}$ for 24 hours and subsequently plated by microdrop on TSA, which was then followed by incubation at $37^{\circ} \mathrm{C}$ for 24 hours.

The experiment was conducted in triplicate with three replications, using positive

Table 1. Proportions used for preparation of the combinations of essential oils for evaluation of bactericidal activity in vitro on enterotoxigenic Escherichia coli.

\begin{tabular}{lcc}
\hline \multirow{2}{*}{ Proportions $^{*}$} & \multicolumn{2}{c}{ Combinations of essential oils (\%) } \\
\cline { 2 - 3 } & $\mathrm{T}: \mathrm{Ci}: \mathrm{O}$ & $\mathrm{T}: \mathrm{Cl}: \mathrm{O}$ \\
\hline $100: 0: 0$ & $0.25: 0: 0$ & $0.25: 0: 0$ \\
$0: 100: 0$ & $0: 0.12: 0$ & $0: 0.50: 0$ \\
$0: 0: 100$ & $0: 0: 0.50$ & $0: 0: 0.50$ \\
$50: 50: 0$ & $0.12: 0.06: 0$ & $0.12: 0.25: 0$ \\
$50: 0: 50$ & $0.12: 0: 0.25$ & $0.12: 0: 0.25$ \\
$0: 50: 50$ & $0: 0.06: 0.25$ & $0: 0.25: 0.25$ \\
$67: 17: 17$ & $0.16: 0.02: 0.08$ & $0.16: 0.08: 0.08$ \\
$17: 67: 17$ & $0.04: 0.08: 0.08$ & $0.04: 0.33: 0.08$ \\
$17: 17: 67$ & $0.04: 0.02: 0.33$ & $0.04: 0.08: 0.33$ \\
$33: 33: 33$ & $0.08: 0.03: 0.16$ & $0.08: 0.16: 0.16$ \\
\hline
\end{tabular}

*Percentage in relation to the minimum bactericidal concentration (MBC) of $0.12 \%$ oil of cinnamon, $0.25 \%$ oil of thyme, and $0.50 \%$ oils of cloves and oregano. T:Ci:O-Thyme:Cinnamon:Oregano; T:Cl:OThyme:Cloves:Oregano. 
controls (TSB with the addition of $0.5 \%$ Tween 80 and culture) for each replication.

\subsection{Bactericidal Action of the Combinations of Essential Oils on ETEC Inoculated in Ground Beef}

The two combinations that showed the best bactericidal action with the lowest concentrations of essential oils, based on greater in vitro bactericidal activity, were then selected: preservative 1 (P1) containing $0.03 \% ; 0.16 \%$ and $0.08 \%$ of the cinnamon, oregano and thyme, respectively and preservative 2 (P2) containing $0.08 \% ; 0.33 \%$ and $0.04 \%$ of the clove, oregano and thyme, respectivaly. The essential oil blends were prepared in glycerol, based on $1 \%$ solutions of the oils.

The quadriceps femoris beef muscle was used for preparation of the fresh ground bovine meat (acquired in the market city of Lavras, Minas Gerais, Brazil). After disinfecting the surface of the packaging with $70 \%$ alcohol, the package was opened, and around $1 \mathrm{~cm}$ of the entire surface area was removed so as to use only the inner part. In an aseptic manner, the meat was cut in pieces of approximately $16 \mathrm{~cm}^{2}$ and ground in a previously sanitized multiprocessor.

Portions of $25 \mathrm{~g}$ of ground beef were placed in sterile plastic bags, and $2.5 \mathrm{~mL}$ of the preservatives were added (final concentration of $0.27 \%$ and $0.45 \%$ for preservative 1 and 2, respectively). The samples were homogenized in a Stomacher homogenizer (490 strokes/min) for 3 minutes. After homogenization, the portions were inoculated with $25 \mu \mathrm{L}$ of standardized ETEC culture (5 LogCFU/g), the plastic bags were sealed, and once more homogenized. A negative control was prepared, containing only ground beef, and a positive control, with ground beef and inoculum.

The samples were stored at $7^{\circ} \mathrm{C}$ for 120 hours. Samplings were made after 6 , 24,72 , and 120 hours of storage. The experiment was performed in triplicate, with three replications.

\subsection{Quantification of ETEC in Ground Beef}

Quantification of ETEC in ground beef was performed by adding $225 \mathrm{~mL}$ of $0.1 \%$ peptone water $(\mathrm{w} / \mathrm{v})$ to the plastic bags containing the $25 \mathrm{~g}$ portions of ground beef, followed by homogenization in a Stomacher blender (490 strokes/min) for 3 minutes. After that, decimal dilutions in $0.1 \%$ peptone water $(\mathrm{w} / \mathrm{v})$ were prepared. Aliquots of $0.1 \mathrm{~mL}$ of the appropriate dilutions were inoculated in Hecktoen Enteric Agar and incubated at $37^{\circ} \mathrm{C}$ for 24 hours, and the typical colonies quantified.

\subsection{Chemical Analysis of the Combinations of Essential Oils}

Chemical analyses of the volatile oils were carried in a gas chromatography system using the Agilent ${ }^{\circledR} 7890^{a}$ chromatograph, operating with an HP GC ChemStation Ver. A.01.14 data processing system, equipped with an automatic injector/sampler CombiPAL Autosampler System (CTC Analytic AG, Switzerland) 
and a Flame Ionization Detector (FID). A fused silica capillary column HP-5MS (30 m length $\times 250 \mu \mathrm{m}$ inner diameter $\times 0.25 \mu \mathrm{m}$ film thickness) (AGILENT ${ }^{\circledR}$, California, USA) was used for separation with a heating interval from $60^{\circ} \mathrm{C}$ to $200^{\circ} \mathrm{C}$, using a temperature ramp rate of $3^{\circ} \mathrm{C} / \mathrm{min}$, followed by a ramp rate of $10^{\circ} \mathrm{C} / \mathrm{min}$ up to $270^{\circ} \mathrm{C}$, remaining in isothermal condition for 1 minute. Samples were prepared in the same trial solution in situ in ethyl acetate. The injection volume was $1.0 \mu \mathrm{L}$ in the split mode at an injection ratio of 50:1. Helium was used as a carrier gas with a flow of $1.0 \mathrm{~mL} / \mathrm{min}$; the temperatures of the injector and of the detector were kept at $240^{\circ} \mathrm{C}$. The combined oils were analyzed in triplicate and constituent concentrations were expressed by the mean of the percentages of the relative area of the chromatographic peaks \pm the standard deviation. Results were provided only for the ten constituents of greatest relative area.

Qualitative analyses were carried out on an Agilent ${ }^{\circledR}$ 7890A chromatograph coupled to a mass selective detector Agilent ${ }^{\circledR}$ MSD 5975C (Agilent Technologies, California, USA), operating by electronic impact ionization at $70 \mathrm{ev}$, in scan mode, at a speed of $1.0 \mathrm{scan} / \mathrm{s}$, with a mass acquisition range of $40-400 \mathrm{~m} / \mathrm{z}$. Operating conditions were the same used in the GC-FID analyses.

Identification of volatile constituents was performed via parallel comparison of retention indices and mass spectra with data stored in the NIST/EPA/NHI library (NIST, 2008) and from the literature [18]. The calculation of the retention indices was made through co-injection with $\mathrm{C}_{8}-\mathrm{C}_{32} n$-alkanes series in line with Van den Dool \& Kratz [19].

\subsection{Physical-Chemical Analyses of the Meat}

\subsection{1. pH}

Readings of $\mathrm{pH}$ were made on the piece of chuck meat before grinding with the aid of a portable potentiometer (Digimed ${ }^{\circledR}$, model DM 20) equipped with a penetration electrode with resolution of 0.01 units of $\mathrm{pH}$. Three readings were made per piece, for a total of nine readings. The result was expressed by the mean \pm standard deviation of all the readings.

\subsubsection{Color}

Objective determination of the final color of the ground beef was made through use of the Konica Minolta ${ }^{\circledR}$ CM-600D portable spectrophotometer. For calculation of color indexes, a $10^{\circ}$ observer angle, D65 illuminant, and the CIELAB color system were established. The color parameters lightness $\left(L^{\star}\right)$, redness $\left(a^{*}\right)$ and yellowness $\left(b^{*}\right)$ were obtained considering the mean value of three readings made at different points of the ground beef of approximately $2 \mathrm{~mm}$ thickness. The saturation indexes $\left(C^{\star}\right)$ and hue angle $\left(h^{\star}\right)$ were calculated by the formulas $C^{\star}=\left(a^{\star 2}+b^{\star 2}\right)^{1 / 2} ; h^{\star}=\tan ^{-1}\left(b^{\star} / a^{\star}\right)[20]$.

\subsection{Statistical Analyses}

The experiment was set up in a completely randomized design (CRD) in a $3 \times 4$ factorial arrangement ( 3 treatments and 4 storage times). Regression analyses 
over time were carried out for each treatment. Results were then subjected to variance analysis (ANOVA), and comparison of means was performed through the Scott Knott test at 5\% significance. Statistical analyses were made using the STATISTICA 5.0 software from STATSOFT. All data were obtained from the three independent experiments in triplicate.

\section{Results and Discussion}

The data on the antimicrobial action of the different oil combinations tested in vitro on ETEC are shown in Table 2.

Based on these results, two combinations that joined the triads with the lowest percentages of essential oils and high bactericidal action in vitro on ETEC were selected for preparing the preservatives. Preference for the lowest concentrations was based on general knowledge that the application of essential oils at high concentrations in food, and specifically in meat, may lead to undesirable sensory changes [21] [22].

Two combinations of essential oils were selected: thyme/cinnamon/oregano (33:33:33) and thyme/cloves/oregano (17:17:67) for analysis in ground beef Table 3. These were designated as preservative 1 (P1) and preservative 2 (P2), respectively.

The action of the essential-oil-based preservatives on ETEC inoculated in ground beef can be observed in Figure 1.

Figure 1 shows that after one day of refrigeration viable ETEC numbers declined in all treatments (control and essential oils treatments), with no significant difference among them. The change of incubation temperature $\left(37^{\circ} \mathrm{C}\right.$ to $7^{\circ} \mathrm{C}$ ) and of culture medium (TSB inoculum to meat micce) induces bacteria to

Table 2. Antimicrobial activity in vitro of the combinations of essential oils at different proportions on enterotoxigenic Escherichia coli.

\begin{tabular}{ccc}
\hline & \multicolumn{2}{c}{ Combinations of the essential oils } \\
\cline { 2 - 3 } Proportions* & T:Ci:O & T:Cl:O \\
\hline $100: 0: 0$ & - & - \\
$0: 100: 0$ & - & - \\
$0: 0: 100$ & - & - \\
$50: 50: 0$ & - & + \\
$50: 0: 50$ & - & - \\
$0: 50: 50$ & - & + \\
$67: 17: 17$ & + & + \\
$17: 67: 17$ & + & + \\
$17: 17: 67$ & + & - \\
$33: 33: 33$ & - & + \\
\hline
\end{tabular}

*Percentage in relation to the minimum bactericidal concentration (MBC) of the essential oils. Cinnamon: 0.12\%; thyme: $0.25 \%$; cloves and oregano: $0.50 \%$. T:Ci:O-Thyme:Cinnamon:Oregano; $\mathrm{T}: \mathrm{Cl}: \mathrm{O}-$ Thyme:Cloves:Oregano. (-) Inhibition of growth. (+) Growth. 
Table 3. Predominant chemical constituents of the combinations of essential oils used in the trials of growth inhibition of enterotoxigenic Escherichia coli in refrigerated ground beef.

\begin{tabular}{cc}
\hline Combination/Proportion & Main constituents (\%) \\
\hline & Carvacrol $(46.23 \pm 0.04)$; Thymol $(16.86 \pm 0.31) ; p$-Cymene \\
& $(10.61 \pm 0.02) ; E$-Cinnamaldehyde $(9.15 \pm 0.09) ;$ Linalool $(3.03$ \\
& $\pm 0.21) ; \gamma$-Terpenine $(2.75 \pm 0.58) ; E$-Caryophyllene $(2.10 \pm$ \\
$0.33) ;$ Borneol $(1.02 \pm 0.07) ;$ Camphor $(0.98 \pm 0.14) ; 1.8$-Cineol \\
Thyme:cinnamon:oregano & $(0.88 \pm 0.03)$ \\
\cline { 2 - 2 } $0.08 \%: 0.03 \%: 0.16 \%$ & Total monoterpenes: $82.36 \%$ \\
& Total sesquiterpenes: $2.10 \%$ \\
Total phenylpropanoids: $\mathbf{9 . 1 5 \%}$ \\
Total constituents identified: $93.61 \%$
\end{tabular}

Carvacrol (56.99 \pm 0.08$)$; Eugenol (12.72 \pm 0.61$)$; Thymol (6.73 $\pm 0.26) ; p$-Cymene (6.18 \pm 0.04$) ; E$-Caryophyllene (3.29 \pm 0.42$)$; Linalool ( $2.30 \pm 0.12) ; \gamma$-Terpenine $(2.03 \pm 0.06)$; Eugenol ace-

Thyme:cloves:oregano 0.04\%:0.08\%:0.33\% tate (1.42 \pm 0.20$) ; \beta$-Pinene (1.01 \pm 0.04$)$; Borneol (0.88 \pm 0.06$)$.

Total monoterpenes: $76.12 \%$

Total sesquiterpenes: $3.29 \%$

Total phenylpropanoids: $14.14 \%$

Total constituents identified: $93.55 \%$

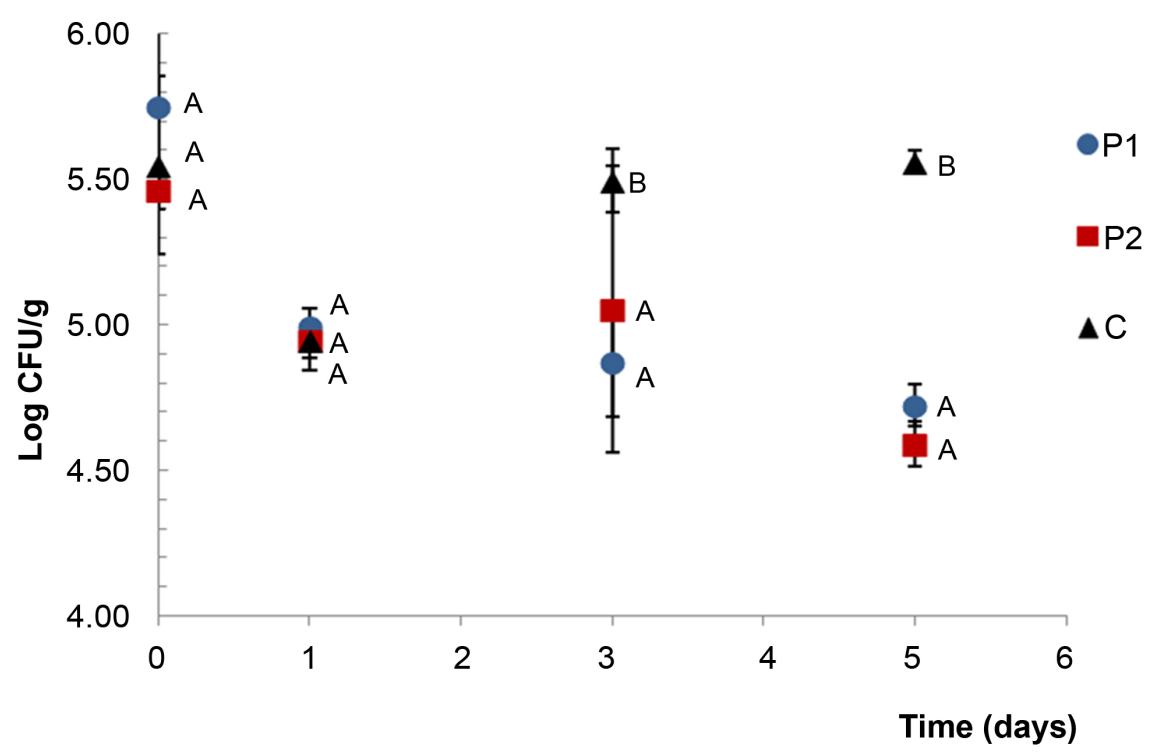

Figure 1. Antimicrobial effect of the blends of essential oils on enterotoxigenic Escherichia coli in ground beef during storage at $7^{\circ} \mathrm{C}$. P1 (thyme $0.08 \%$; cinnamon $0.03 \%$; oregano $0.16 \%$ ). P2 (thyme $0.04 \%$; cloves $0.08 \%$; oregano $0.33 \%$ ). C (without essential oil). Values (Log CFU/g) with the same capital letters, in the same time, do not differ among themselves ( $\mathrm{p} \leq 0.05)$.

alter their metabolism, entering the lag phase, wherein it's often difficult to induce recovery under culture mediums, mainly because ETEC is mesophilic. However, starting on second day, there were significant differences among the number of colonies obtained under control treatment and under essential oils treatments that had previously not differed amosng themselves. This result 
shows the action of the essential oils employed. After the fifth day of storage at $7^{\circ} \mathrm{C}$, the difference between the number of colonies obtained from control samples and those obtained from essential oils treatments increased, with no significant difference among them. Another factor that influences essential oils' antimicrobial activity is incubation temperature. $7^{\circ} \mathrm{C}$ is inappropriate for ETEC growth, as it promotes the decline of cytoplasmatic membrane fluidity-a decline which account for a decrease of interation between the bacteria and the essential oils.

The two preservatives (P1 and P2) used, exhibited significant bactericidal action ( $\mathrm{p}<0.05)$ on ETEC in relation to the control (ground beef with ETEC, and without essential oil). Although ETEC was not eliminated from the ground beef, there was a reduction of ETEC of 1.03 and of $0.87 \mathrm{LogCFU} / \mathrm{g}$ in the samples with the addition of $\mathrm{P} 1$ and $\mathrm{P} 2$, respectively.

As for the meat samples without addition of preservatives, a practically constant number for ETEC (increase of $0.01 \mathrm{LogCFU} / \mathrm{g}$ ) was observed throughout the time of storage. The storage temperature of $7^{\circ} \mathrm{C}$ only inhibited the growth of the bacteria on the meat, but did not act as a bactericide. Growth of ETEC on the non-inoculated and witout essential oils samples was not observed.

Although there was a significant effect of the preservatives on ETEC in meat, the bactericidal action was less than that observed in vitro. This reduction in antimicrobial activity is widely known, and was compiled in a review article on the use of essential oils as antimicrobial agents in meat and meat products carried out by Jayasena \& Jo [15]. Studies show that foods with higher fat contents need greater concentrations of essential oils for antimicrobial activity to be effective, because the oils may migrate toward the fat. In addition, meat proteins exercise a protective effect on the microorganisms, lowering essential oil efficiency [23] [24].

Analyses by GC-MS of the preservatives show 21 and 24 constituents in reference to the combinations of the oils of thyme/cinnamon/oregano (P1) and thyme/cloves/oregano (P2), respectively.

Table 4 describes the ten constituents of greatest relative area from analysis of the combinations, which represented $93.61 \%$ and $93.55 \%$ of the total chemical composition. Both combinations of oils consisted mainly of monoterpenes (more than $76 \%$ of the total chemical composition). In both preservatives there was a predominance of carvacrol, a constituent of the essential oil of $O$. vulgare (73.11\%), employed in this study [17], as well as a high concentration of thymol.

The bactericidal action of preservatives P1 and P2 on ETEC in ground beef may be related to the synergistic action of carvacrol and thymol.

Carvacrol and thymol are terpenoids that have a high capacity for disrupting the external membrane of Gram negative bacteria, probably due to the presence of hydroxyl groups in the phenolic molecule. Studies with carvacrol have shown that its presence in a culture medium promotes the release of lipopolysaccharides from the external membrane and interferes with the permeability of the cytoplasmic membrane to ions [8]. 
Table 4. Objective Variation in Color of Ground Beef Containing Blends of Essential Oils over Five Days of Storage at $7^{\circ} \mathrm{C}$.

\begin{tabular}{|c|c|c|c|c|}
\hline \multirow{2}{*}{ Parameter } & \multirow{2}{*}{ Time (days) } & \multicolumn{3}{|c|}{ Treatments ${ }^{* *}$} \\
\hline & & P1 & P2 & $\mathrm{C}$ \\
\hline \multirow[t]{4}{*}{$a^{*}$} & 0 & $10.073^{\mathrm{Aa}}$ & $9.827^{\mathrm{Aa}}$ & $12.393^{\mathrm{Cb}}$ \\
\hline & 1 & $11.233^{\mathrm{Aa}}$ & $11.650^{\mathrm{Ba}}$ & $11.313^{\mathrm{Ca}}$ \\
\hline & 3 & $11.027^{\mathrm{Aa}}$ & $13.080^{\mathrm{Bb}}$ & $9.430^{\mathrm{Ba}}$ \\
\hline & 5 & $9.767^{\mathrm{Ab}}$ & $11.783^{\mathrm{Bb}}$ & $5.667^{\mathrm{Aa}}$ \\
\hline \multirow[t]{4}{*}{$b^{*}$} & 0 & $13.563^{\mathrm{Ab}}$ & $11.347^{\mathrm{Aa}}$ & $15.637^{\mathrm{Bc}}$ \\
\hline & 1 & $13.380^{\mathrm{Aa}}$ & $13.617^{\mathrm{Ba}}$ & $14.277^{\mathrm{Ba}}$ \\
\hline & 3 & $14.790^{\mathrm{Ba}}$ & $16.310^{\mathrm{Cb}}$ & $14.610^{\mathrm{Ba}}$ \\
\hline & 5 & $12.710^{\mathrm{Aa}}$ & $13.673^{\mathrm{Ba}}$ & $12.197^{\mathrm{Aa}}$ \\
\hline \multirow[t]{4}{*}{$C^{*}$} & 0 & $16.917^{\mathrm{Ab}}$ & $15.013^{\mathrm{Aa}}$ & $19.970^{\mathrm{Cc}}$ \\
\hline & 1 & $17.473^{\mathrm{Aa}}$ & $17.920^{\mathrm{Ba}}$ & $18.223^{\mathrm{Ba}}$ \\
\hline & 3 & $18.463^{\mathrm{Aa}}$ & $20.807^{\mathrm{Cb}}$ & $17.390^{\mathrm{Ba}}$ \\
\hline & 5 & $16.053^{\mathrm{Ab}}$ & $17.093^{\mathrm{Bb}}$ & $13.450^{\mathrm{Aa}}$ \\
\hline \multirow[t]{4}{*}{$h^{*}$} & 0 & $53.307^{\mathrm{Aa}}$ & $49.107^{\mathrm{Aa}}$ & $51.603^{\mathrm{Aa}}$ \\
\hline & 1 & $50.107^{\mathrm{Aa}}$ & $49.453^{\mathrm{Aa}}$ & $51.580^{\mathrm{Aa}}$ \\
\hline & 3 & $53.377^{\mathrm{Ab}}$ & $49.547^{\mathrm{Aa}}$ & $57.200^{\mathrm{Bb}}$ \\
\hline & 5 & $52.477^{\mathrm{Aa}}$ & $52.107^{\mathrm{Aa}}$ & $65.083^{\mathrm{Cb}}$ \\
\hline \multirow[t]{4}{*}{$L^{*}$} & 0 & $45.313^{\mathrm{Bb}}$ & $39.240^{\mathrm{Aa}}$ & $44.367^{\mathrm{Ab}}$ \\
\hline & 1 & $40.717^{\mathrm{Aa}}$ & $39.757^{\mathrm{Aa}}$ & $42.847^{\mathrm{Ab}}$ \\
\hline & 3 & $43.833^{\mathrm{Ba}}$ & $42.363^{\mathrm{Ba}}$ & $44.950^{\mathrm{Aa}}$ \\
\hline & 5 & $39.740^{\mathrm{Aa}}$ & $43.203^{\mathrm{Bb}}$ & $46.770^{\mathrm{Bc}}$ \\
\hline
\end{tabular}

${ }^{*} \mathrm{P} 1$ : thyme $0.08 \%$; cinnamon $0.03 \%$; oregano $0.16 \%$. P2: thyme $0.04 \%$; cloves $0.08 \%$; oregano $0.33 \%$. C: Control (without essential oils). For each colour indice, means with different capital letters (A-C) in the same column are significantly different between storage duration $(\mathrm{p} \leq 0.05)$. For each colour indice, means with different lowercase letters $(\mathrm{a}-\mathrm{c})$ in the same line are significantly different between treatments ( $\mathrm{p} \leq$ 0.05).

Carvacrol $(30 \mathrm{mg} / \mathrm{mL})$ proved to be effective in inhibiting the growth of $E$. coli inoculated in beef carcass [25]. However, the presence of other components, in addition to carvacrol and thymol, even at low concentrations, may promote synergistic, additive, or antagonistic interactions [26]. In this study, the mixtures of the essential oils of thyme, oregano, and cinnamon (P1) and thyme, cloves, and oregano (P2) led to a reduction in ETEC in ground beef even at low final concentrations $(0.27 \%$ and $0.45 \%$, respectively) in the product, suggesting synergistic action.

Nevertheless, the two preservatives showed similar performance on inhibiting ETEC growth in ground beef, the essential oil concentration of preservative P1 $(0.27 \%)$ was $60 \%$ of the concentration of preservative P2 (0.45\%). This shows that the combination of oils of thyme, cinnamon, and oregano exhibited a great- 
er antimicrobial effect than the combination containing thyme, cloves, and oregano. This result may have occurred due to greater concentration of terpenes in preservative $\mathrm{P} 1$ than in $\mathrm{P} 2$.

The mean $\mathrm{pH}$ of the meat used in the experiment was $5.74 \pm 0.02$, within normal values.

The preservatives added did not compromise the color of the ground beef, and the product remained with good appearance over the five days of storage (Table 4). This result is important, given that color is the first sensory characteristic appraised by the consumer, and its acceptance or rejection determines whether the meat pleases consumers or not [27].

The red index $\left(a^{*}\right)$ is one of the fundamental parameters in the evaluation of the characteristic color of cured meat products, since it denotes the variation from green to red. A sharp decline in the values of $a^{*}$ of the meat without essential oils can be observed in Table 4, showing the change of its hue from red to greenish. However, in meat with the addition of essential oils, an increase was observed in the values of $a^{*}$ up to the third day of storage, followed by a small decline. The results show that the pigments associated with coloring of the meat were probably not oxidized during the storage period. The addition of essential oils to the meat did not significantly change the values of $b^{\star}$ (yellowness) over time; however, in the control, the values of this parameter decreased over the time of storage, tending toward blue. The yellow index $\left(b^{\star}\right)$ represents shades ranging from blue (negative values) to yellow (positive values).

The chroma $\left(C^{*}\right)$ and the hue angle $\left(h^{*}\right)$ parameters, both based on the $a^{*}$ and $b^{*}$ values, were significantly affected by the time of storage of the meat without addition of essential oils. The reduction in the values of $C^{*}$ and the increase in $h^{\star}$ indicate that the meat lost its intense red coloring. However, the addition of the preservatives had a positive influence on the color of the meat, without significant variation in these values during storage of the ground beef with the addition of P1 and slight variation only in $h^{*}$ in the meat with the addition of P2.

Preservative $\mathrm{P} 1$ led to a reduction in $L^{*}$ values, indicating that the meat darkened during the time of storage. In contrast, preservative P2 led to an increase in lightness $\left(L^{\star}\right)$, and the appearance was better than at the beginning of the experiment. However, the control, which did not have essential oils, showed a positive difference only in regard to lightness $\left(L^{\star}\right)$.

The antioxidant activity of essential oils is widely known, and this activity is an important factor in maintaining the color of meat and meat products [28]. It is known that one of the factors that causing degradation of the coloring of meat is associated with the presence of free radicals that lead to production of aldehydes. They promote oxidation of myoglobin and oxymyoglobin, leading to the formation of metmyoglobin, imparting a brown color to the meat [29].

The combinations of essential oils had synergistic antimicrobial effects on ETEC in the study in vitro and, when added to ground beef, this effect continued, although in a reduced manner. The use of combinations of essential oils 
promoted conservation of the color of the ground beef. New studies are necessary to ascertain whether other combinations of essential oils would be more effective against ETEC at the same, or lower, concentrations than those used in this study.

\section{Conclusion}

Preservative P1 containing oils of thyme, cinnamon, and oregano had better performance than preservative P2 against ETEC. The two blends of essential oils used in ground beef showed significant action both as preservatives and antioxidants, maintaining the color of ground beef at $7^{\circ} \mathrm{C}$ for 5 days.

\section{Acknowledgements}

To the Fundação de Amparo à Pesquisa do Estado de Minas Gerais (FAPEMIG), the Coordenação de Aperfeiçoamento de Pessoal de Nível Superior (CAPES), and the Conselho Nacional de Desenvolvimento Científico e Tecnológico (CNPq) for financial support and granting of scholarships.

\section{Conflicts of Interest}

The authors declare no conflicts of interest regarding the publication of this paper.

\section{References}

[1] Nataro, J.P. and Kaper, J.B. (1998) Diarrheagenic Escherichia coli. Clinical Microbiology Reviews, 11, 142-201. https://doi.org/10.1128/CMR.11.1.142

[2] Banwart, G.J. (1998) Basic Food Microbiology. Springer, Boston, MA. https://doi.org/10.1007/978-1-4684-6453-5

[3] von Mentzer, A., Connor, T.R., Wieler, L.H., Semmler, T., Iguchi, A., Thomson, N.R., et al. (2014) Identification of Enterotoxigenic Escherichia coli (ETEC) Clades with Long-Term Global Distribution. Nature Genetics, 46, 1321-1326. https://doi.org/10.1038/ng.3145

[4] Cho, S.H., Kim, J., Oh, K.-H., Hu, J.K., Seo, J., Oh, S.S., et al. (2014) Outbreak of Enterotoxigenic Escherichia coli O169 Enteritis in Schoolchildren Associated with Consumption of Kimchi, Republic of Korea, 2012. Epidemiology \& Infection, 142, 616-623. https://doi.org/10.1017/S0950268813001477

[5] Aziz, M. and Karboune, S. (2016) Natural Antimicrobial/Antioxidant Agents in Meat and Poultry Products as Well as Fruits and Vegetables: A Review. Critical Reviews in Food Science and Nutrition, 58, 486-511. https://doi.org/10.1080/10408398.2016.1194256

[6] Pateiro, M., et al. (2018) Essential Oils as Natural Additives to Prevent Oxidation Reactions in Meat and Meat Products: A Review. Food Research International, 113, 156-166. https://doi.org/10.1016/j.foodres.2018.07.014

[7] Bakkali, F., Averbeck, S., Averbeck, D. and Idaomar, M. (2008) Biological Effects of Essential Oils-A Review. Food and Chemical Toxicology, 46, 446-475. https://doi.org/10.1016/j.fct.2007.09.106

[8] Nazzaro, F., Fratianni, F., De Martino, L., Coppola, R. and De Feo, V. (2013) Effect 
of Essential Oils on Pathogenic Bacteria. Pharmaceuticals, 6, 1451-1474. https://doi.org/10.3390/ph6121451

[9] de Oliveira, T.L.C., de AraújoSoares, R. and Piccoli, R.H. (2013) A Weibull Model to Describe Antimicrobial Kinetics of Oregano and Lemongrass Essential Oils against Salmonella Enteritidis in Ground Beef during Refrigerated Storage. Meat Science, 93, 645-651. https://doi.org/10.1016/j.meatsci.2012.11.004

[10] Höferl, M., Buchbauer, G., Jirovetz, L., Schmidt, E., Stoyanova, A., Denkova, Z., et al. (2009) Correlation of Antimicrobial Activities of Various Essential Oils and Their Main Aromatic Volatile Constituents. Journal of Essential Oil Research, 21, 459-463. https://doi.org/10.1080/10412905.2009.9700218

[11] Rasschaert, G., Houf, K. and De Zutter, L. (2006) Impact of the Slaughter Line Contamination on the Presence of Salmonella on Broiler Carcasses. Journal of Applied Microbiology, 103, 333-341. https://doi.org/10.1111/j.1365-2672.2006.03248.x

[12] Santurio, D.F., et al. (2011) Atividade antimicrobiana de óleos essenciais de condimentos frente a amostras de Escherichia coli isoladas de aves e bovinos. Ciência Rural, 41, 1051-1056. https://doi.org/10.1590/S0103-84782011005000067

[13] Smith-Palmer, A., Stewart, J. and Fyfe, L. (2001) The Potential Application of Plant Essential Oils as Natural Food Preservatives in Soft Cheese. Food Microbiology, 18, 463-470. https://doi.org/10.1006/fmic.2001.0415

[14] Burt, S. (2004) Essential Oils: Their Antibacterial Properties and Potential Applications in Foods-A Review. International Journal of Food Microbiology, 94, 223-253. https://doi.org/10.1016/j.ijfoodmicro.2004.03.022

[15] Jayasena, D.D. and Jo, C. (2013) Essential Oils as Potential Antimicrobial Agents in Meat and Meat Products: A Review. Trends in Food Science \& Technology, 34, 96-108. https://doi.org/10.1016/j.tifs.2013.09.002

[16] Jayari, A., El Abed, N., Jouini, A., Abdul-Wahab, O.M.S., Maaroufi, A. and Ahmed, S.B.H. (2018) Antibacterial Activity of Thymus capitatus and Thymus algeriensis Essential Oils against Four Food-Borne Pathogens Inoculated in Minced Beef Meat. Journal of Food Safety, 38, e12409. https://doi.org/10.1111/jfs.12409

[17] Souza, A.A. (2015) Análise química e potencial antimicrobiano de óleos essenciais sobre Escherichia coli enterotoxigênica na conservação de carne moída. Universidade Federal de Lavras, Lavras.

[18] Adams, R.P. (2007) Identification of Essential Oil Components by Gas Chromatography/Mass Spectroscopy. 4th Edition, Allured Publishing Corporation, Illinois, $803 \mathrm{p}$.

[19] van Den Dool, H. and Kratz, P.D. (1963) A Generalization of the Retention Index System Including Linear Temperature Programmed Gas-Liquid Partition Chromatography. Journal of Chromatography A, 11, 463-471.

https://doi.org/10.1016/S0021-9673(01)80947-X

[20] Ramos, E.M. and Gomide, L.A.M. (2009) Avaliação da Qualidade de Carnes: Fundamentos e Metodologias. 1st Editoin, Editora UFV, Viçosa.

[21] Govaris, A., Solomakos, N., Pexara, A. and Chatzopoulou, P.S. (2010) The Antimicrobial Effect of Oregano Essential Oil, Nisin and Their Combination against Salmonella Enteritidis in Minced Sheep Meat during Refrigerated Storage. International Journal of Food Microbiology, 137, 175-180.

https://doi.org/10.1016/j.ijfoodmicro.2009.12.017

[22] Hayouni, E.A., Chraief, I., Abedrabba, M., Bouix, M., Leveau, J.Y. and Mohammed, 
H., et al. (2008) Tunisian Salvia officinalis L. and Schinus molle L. Essential Oils: Their Chemical Compositions and Their Preservative Effects against Salmonella Inoculated in Minced Beef Meat. International Journal of Food Microbiology, 125, 242-251. https://doi.org/10.1016/j.ijfoodmicro.2008.04.005

[23] Gill, A.O., Delaquis, P., Russo, P. and Holley, R.A. (2002) Evaluation of Antilisterial action of Cilantro Oil on Vacuum Packed Ham. International Journal of Food Microbiology, 73, 83-92. https://doi.org/10.1016/S0168-1605(01)00712-7

[24] Tserennadmid, R., Takó, M., Galgóczy, L., Papp, T., Vágvölgyi, C., Gerő, L., et al. (2010) Antibacterial Effect of Essential Oils and Interaction with Food Components. Central European Journal of Biology, 5, 641-648.

[25] Souza, A.A., Dias, N.A.A., Piccoli, R.H. and Bertolucci, S.K.V. (2016) Composição química e concentração mínima bactericida de dezesseis óleos essenciais sobre Escherichia coli enterotoxigênica. Revista Brasileira de Plantas Medicinais, 18, 105-112. https://doi.org/10.1590/1983-084X/15_050

[26] McDonnell, M.J., Rivas, L., Burgess, C.M., Fanning, S. and Duffy, G. (2012) Evaluation of Carvacrol for Control of Escherichia coli O157 on Cattle Hide and Carcass Cuts. Foodborne Pathogens and Disease, 9, 1049-1052.

https://doi.org/10.1089/fpd.2012.1224

[27] Chorianopoulos, N., Kalpoutzakis, E., Aligiannis, N., Mitaku, S., Nychas, G.-J. and Haroutounian, S.A. (2004) Essential Oils of Satureja, Origanum, and Thymus Species: Chemical Composition and Antibacterial Activities against Foodborne Pathogens. Journal of Agricultural and Food Chemistry, 52, 8261-8267. https://doi.org/10.1021/jf049113i

[28] Cornforth D. (1994) Color-Its Basis and Importance. In: Pearson, A.M. and Dutson, T.R., Eds., Quality Attributes and their Measurement in Meat, Poultry and Fish Products, Springer, Boston, MA, 34-78. https://doi.org/10.1007/978-1-4615-2167-9_2

[29] Fasseas, M.K., Mountzouris, K.C., Tarantilis, P.A., Polissiou, M. and Zervas, G. (2008) Antioxidant Activity in Meat Treated with Oregano and Sage Essential Oils. Food Chemistry, 106, 1188-1194. https://doi.org/10.1016/j.foodchem.2007.07.060 